\title{
Behavioural Differences of High and Low Performing Teams: A Multi-InSTITUtional Study OF First-Year ENGINEERING DESIGN TEAMS
}

\author{
Patricia K. Sheridan ${ }^{a, b}$, Adam Goodman ${ }^{a}$, Todd Murphy ${ }^{a}$, Doug Reeve ${ }^{b}$, Greg Evans ${ }^{b}$ \\ ${ }^{a}$ Center for Leadership, McCormick School of Engineering, Northwestern University, \\ ${ }^{\mathrm{b}}$ Institute for Leadership Education in Engineering, Faculty of Applied Science and Engineering, University of Toronto \\ patricia.sheridan@utoronto.ca
}

\begin{abstract}
This paper compares student intra-team feedback to identify behaviours that differentiate high and low performing teams. Data from two universities' firstyear engineering design courses was analysed and demonstrated that the ways in which students discussed high and low performing teams was similar. This paper discusses some of the issues with which low performing teams struggled. Both high and low performing teams experienced a lack of quality and quantity of communication, whereas low-performing teams struggled with hoarding work, leveraging team members and supporting others. High-performing teams may have a more collective team mindset that values the skills and perspectives of all team members more.
\end{abstract}

Keywords: teamwork, first-year engineering, engineering design, team performance.

\section{INTRODUCTION}

$\mathrm{CEAB}$ and $\mathrm{ABET}$ accreditation requirements require teamwork to become a central component of Engineering Education [1], [2]. Typically, teamwork is incorporated into the design curriculum through team-based projects that enabling students to address complex challenges in real-world situations. These projects introduce students to the technical and behavioural challenges that model what they will experience post-graduation.

Design-team work requires high interdependence amongst the team members, as these complex challenges cannot be subdivided into smaller components that can be independently executed [3]. As a result, teams need to develop a sense of coherence in the process of how they will work before they can create a coherent work product (or design). Higher levels of coherence among team members mental models has been linked to greater team performance [4].

However, students often struggle to create these processes or models of how to work effectively together, resulting in a poor team experience. Instructors can spend substantial extra-hours supporting dysfunctional teams, and students who have bad team experiences learn to dislike working in teams [5]. To combat this problem, research has focused on identifying and developing approaches to minimize students' negative team processes (see review in [6]).

This study looks to identify the behaviours that differentiate high and low performing teams as discussed in student mid-project, feedback. Data from two universities' first-year engineering design courses was analysed and demonstrated that despite being asked different questions in their mid-project feedback, the ways in which students discussed issues in high and low performing teams was similar. This paper discusses the issues that teams struggled with, and discusses potential sources of the issues encountered.

\section{TEAMWORK CONTEXT}

This study compares student discussion of teamwork behaviours in their first-year engineering design courses at two universities - the University of Toronto and Northwestern University. Both first-year programs have a two-course design sequence in which students work with a client to develop a design that meets their needs. Students in one program focus on developing a conceptual design with documentation. In the second program there is an additional focus on the fabrication of a working prototype to be given to their client. Both first-year design courses take place in large classes of 900 and 450 students, respectively. Teams range in size from 4-6 students.

The University of Toronto's Institute for Leadership Education in Engineering (ILead) and Northwestern University's Center for Leadership (CfL) have worked with their respective first-year engineering design courses to develop ways to support student instructors in developing effective teams.

ILead has focused on the development of 12 teammember effectiveness behaviours in students under the premise that creating more effective team members will result in more effective teams [7], [8]. These twelve behaviours comprise ILead's team-effectiveness inventory 
(TEI). The CfL focused on having students differentiate project contributions from process contributions as a way of identifying how to make the team more effective through individual and team-level development goals [9], [10]. While the frameworks underlying the two universities processes were different, their implementation was similar. Both organisations required students to provide some textual self- and peer-assessments of all team-members at the mid-point and end of each project. As a result of the similarities in the design course contexts and feedback processes students' teamwork experiences are comparable

\section{STUDY DESIGN AND METHODS}

This mixed-methods study compares the content of first-year engineering design students' intra-team feedback to determine which behaviours contribute to making effective teams. The datasets from each university were pre-existing from separate studies conducted independently at each institution.

Teams in which there was full-team-consent to participate in the previous studies were included for analysis in this study. This resulted in 55 teams for analysis from the University of Toronto, and 48 teams from Northwestern University. To differentiate high from low performing teams we compared the feedback of the top $10 \%$ of teams to the bottom $10 \%$ of teams. This resulted in five teams being analysed from each institution at each level, for a total of 20 teams.

High and low performing teams were identified differently at each institution based on the quantitative data available from the mid-project feedback process. From the University of Toronto, self- and peer-assessments along the 12 behavioural indicators were available. A team average was calculated (average of 12 behaviours across 4-6 team members with 4-6 assessments per team member based on team size). All 55 teams were then sorted and the top five teams and bottom five teams selected for analysis. From the Northwestern University data, a split question of project contributions was used to determine high and low performing teams (divide 100 points across team members based on their contributions). As all teams had four team members, five random teams which had a standard deviation of zero were categorised as the high teams, and the five teams with the largest standard deviation across contributions were selected as the bottom five teams.

Qualitative self- and peer-assessments from these 20 teams were then analysed to determine the behavioural differences. This resulted in analysing the feedback of 97 students and 436 pieces of feedback which each contained multiple items. At the University of Toronto students were asked to "Please provide some comments to yourself and your peers based on your team effectiveness over the course of this project.". At Northwestern University students were asked to report the 'process contributions' of each team member and 'one development goal' for them to work on to improve their behaviour.

Student responses to these questions were then coded according to ILead's TEI [7]. Additionally, behaviours were coded according to whether they were discussed positively (as contributing to the team's effectiveness) or negatively (as detracting from the team's effectiveness). Emergent codes were developed as trends in feedback surfaced during the analysis.

To differentiate how these behaviours manifest in high and low performing teams both the behaviour and the way it was discussed were recorded for each student. Observations as to how the behaviours were discussed differently between the two groups were developed.

\section{BEHAVIOURAL DIFFERENCES}

A comparison of the self- and peer-assessments demonstrated that, despite asking different questions, the students in both universities discussed teamwork behaviours similarly for high and low performing teams. Table 1 describes the number of items discussed that corresponded to the TEI behaviours.

Table 1: Number of feedback items categorised by the 12 TEl behaviours.

\begin{tabular}{|l|c|c|c|c|}
\cline { 2 - 5 } \multicolumn{1}{c|}{} & \multicolumn{2}{c|}{$\begin{array}{c}\text { Negative } \\
\text { comment }\end{array}$} & \multicolumn{2}{c|}{$\begin{array}{c}\text { Positive } \\
\text { comment }\end{array}$} \\
\cline { 2 - 5 } \multicolumn{1}{c|}{} & $\begin{array}{c}\text { High } \\
\text { Team }\end{array}$ & $\begin{array}{c}\text { Low } \\
\text { Team }\end{array}$ & $\begin{array}{c}\text { High } \\
\text { Team }\end{array}$ & $\begin{array}{c}\text { Low } \\
\text { Team }\end{array}$ \\
\hline $\begin{array}{l}\text { Attend Team } \\
\text { Meetings Prepared }\end{array}$ & 6 & 11 & 10 & 20 \\
\hline $\begin{array}{l}\text { Do their Fair Share } \\
\text { of the Work }\end{array}$ & 9 & 41 & 19 & 37 \\
\hline $\begin{array}{l}\text { Deliver Work on } \\
\text { Time }\end{array}$ & 13 & 35 & 29 & 21 \\
\hline $\begin{array}{l}\text { Help to Plan and } \\
\text { Organise Workflow }\end{array}$ & 15 & 37 & 32 & 30 \\
\hline $\begin{array}{l}\text { Raise Contentious } \\
\text { Issues in a } \\
\text { Constructive Way }\end{array}$ & 2 & 12 & 2 & 5 \\
\hline $\begin{array}{l}\text { Exchange } \\
\text { Information in a } \\
\text { Timely Manner }\end{array}$ & 15 & 26 & 9 & 11 \\
\hline $\begin{array}{l}\text { Openly Express } \\
\text { Ideas and Opinions }\end{array}$ & 34 & 51 & 35 & 24 \\
\hline $\begin{array}{l}\text { Promote Productive } \\
\text { Discussion }\end{array}$ & 15 & 48 & 18 & 18 \\
\hline $\begin{array}{l}\text { Demonstrate } \\
\text { Accountability }\end{array}$ & 2 & 8 & 5 & 6 \\
\hline $\begin{array}{l}\text { Seek and Include } \\
\text { the Input of Others }\end{array}$ & 2 & 19 & 3 & 6 \\
\hline $\begin{array}{l}\text { Show Respect to } \\
\text { Team Members }\end{array}$ & 0 & 9 & 2 & 5 \\
\hline $\begin{array}{l}\text { Listen and Pay } \\
\text { Attention }\end{array}$ & 8 & 13 & 7 & 7 \\
\hline
\end{tabular}


As can be seen in Table 1 (shaded in grey) there were seven behaviours which presented a notable difference in the number of negative comments between high and low performing teams. For almost all of these behaviours, in terms of positive comments there were either similar numbers between high and low performing teams, or more positive comments for high performing teams.

Reviewing the feedback for these seven behaviours, ten issues described the differences observed in student feedback. These issues are presented below in Table 2, clustered under three umbrella themes. Some teamwork issues were experienced by both low and high performing teams. In these cases, while the same issues were present, they were discussed in greater amount in low-performing teams. For issues that were different, these were seen only in the type of team described in Table 2.

Table 2: Issues that surfaced in student feedback grouped by theme and the teams that received them.

\begin{tabular}{|l|c|}
\hline $\begin{array}{l}\text { Issues discussed in student feedback } \\
\text { grouped by theme }\end{array}$ & $\begin{array}{c}\text { Team } \\
\text { type }\end{array}$ \\
\hline 1. Organisation of the team's work \\
\hline a. Needing to do more work than assigned & Both \\
\hline b. Difficulty working ahead of deadlines & Both \\
\hline c. Difficulty scheduling meetings & High \\
\hline d. Hoarding of work & Low \\
\hline 2. Quantity and quality of communication \\
\hline e. Not speaking up in person or online & Both \\
\hline f. Not checking in or sharing information & Both \\
\hline \multicolumn{2}{|c|}{ between meetings } \\
\hline g. Getting distracted during discussion & Both \\
\hline h. Appreciation of Team Member's Contributions \\
\hline h. Asking for help discouraged & Low \\
\hline i. Being closed to others' opinions & Low \\
\hline j. Leveraging others' skills for the team & High \\
\hline
\end{tabular}

Each issue is discussed below, with quotes from student feedback that exemplify it's manifestation. For situations in which the issue was experienced by both high and low performing teams, any differences in the ways the issues were discussed is highlighted.

\subsection{Organisation of the team's work}

This theme represents comments from a combination of three TEI behaviours: a) does their fair share of the work, b) delivers their work on time, and c) helps to plan and organise the workflow. Within these behaviours students discussed the amount of work students completed with respect to their expected amount, how far in advance of deadlines students worked, and how work was decided to be divided amongst the team members.

The first issue that clearly emerged was that doing the work that was assigned to you was not sufficient to be seen of as doing your fair share of the work. This was discussed in both low- and high-performing team members feedback. Despite spending time allocating work amongst team members, those who only completed the work that they were assigned were critiqued for doing so. There appeared to be an implicit expectation that students would do their work, and help others with theirs. Some students also received critiques that they did not take up unexpected work when it arose despite having completed their assigned work. As can be seen from the examples in Table 3 in lowperforming teams it was complained about as something the team member did not do, whereas in high-performing teams this was stated as a suggestion to enhance the team's work.

Table 3: Student quotes about needing to do more work than assigned.

\begin{tabular}{l}
\hline Low-performing team: \\
\hline "She basically didn't do anything other than \\
her own assigned part." \\
"Be more communicative with the team. If you \\
don't have something to do get a task to \\
complete." \\
\hline High-performing team: \\
"You need to work harder! although you are \\
about the project but you need to spend more \\
time on it!" \\
"Try to help out with other's work more."
\end{tabular}

The second issue that emerged was students struggling to work in advance of deadlines. This was discussed in both low- and high-performing team members feedback, however it was discussed differently. Students on lowperforming teams discussed work being submitted late in the night with course deadlines nearly being missed whereas high-performing teams discussed this as an impediment to having the team review and improve the work pre-submission, Table 4.

Table 4: Student quotes about not working in advance of deadlines.

Low-performing team:
"He often does work late at night, or soon
before the deadline, which can be stressful for
other group members."
"he promised to do a certain part by a certain
time. They were never done and another
team member did said part. All team members
were working on the project ... did not get on
until very late in the evening."

\begin{tabular}{l}
\hline High-performing team: \\
\hline "it would be best if he worked towards having \\
the feedback implemented in a faster time \\
window ... written deliverables build on past \\
ones, and implementing feedback quickly is \\
crucial for the success of future deliverables." \\
"I could work on things ahead of time to give \\
my team more resources to reflect on."
\end{tabular}


Table 5: Student quotes about difficulties in scheduling. "Difficult to meet due to busy schedules"

"It would be nice if he were able to attend user meetings, but he often has conflicts"

The fourth issue that emerged was only apparent in lowperforming teams, and was that some students actively prevented an even distribution of work across teammembers. Given the definition of low-performing teams used, issues in workload distribution were expected. However, it was unexpected that hoarding rather than social loafing would have been the source. Feedback discussed both hoarding work from the beginning and taking it over as the project progressed, Table 6 . As a result, some students fell behind and could not meet their deadlines, while others were left without work to do. This issue combined with the expectation of doing more than one's assigned work presents an interesting dichotomy of expectations. In low-performing teams work was described of as not being equitable but that all were still expected to do more than assigned.

Table 6: Student quotes about work not being evenly distributed

"Sometimes I feel that [he] actually gives himself too much work because he is so invested in the project that he wants to make sure it is done well. This means that sometimes, the other group members have less of an idea of the project's progress."

"Tries to take over everything in the project."

This hoarding behaviour is in stark contrast to the desire of high-performing teams to have more meetings to collectively work on the project. High-performing teams appeared to have a desire to leverage all team members to create the best work for the team, whereas low-performing teams appeared not to work from the perspective that everyone on the team could do the work.

\subsection{Quantity and Quality of Communication}

This theme represents comments from a combination of three TEI behaviours: a) exchange information in a timely manner, b) openly express ideas and opinions, c) promote productive discussion. These behaviours were discussed in similar ways between high- and low-performing teams, although they were more prominent in low-performing teams' feedback.

The first issue that emerged was the quantity of communication that students provided. In person, students were critiqued for being quiet, not speaking up in team meetings, or not providing enough ideas during brainstorming sessions. In between meetings, this surfaced as complaints that students were not checking their
GroupMe, or Facebook Group and weren't responding to team member's text messages/emails.

Table 7: Student quotes about limited quantity of communication.

\begin{tabular}{l}
\hline Low-performing team: \\
\hline "I would like to see you contributing more to \\
team discussions. Try to make an effort to \\
interact more..... know you are very capable \\
of doing so." \\
"try not to wait until the period before class to \\
ask questions or relay information to the rest \\
of the team." \\
\hline High-performing team: \\
"he could sometimes speak up more at \\
meetings because he has great ideas!" \\
"I should try to be more proactive in the group \\
chat and remember to respond more quickly."
\end{tabular}

The second issue that emerged was the quality of communication during team meetings (either online or in person). Staying focused on the topic at hand during discussions was the greatest detractor from high quality communication. Students were critiqued on the frequency that they went off topic, that they weren't always attentive enough to the conversation to provide high-quality input, or that they got distracted during conversations by their smartphones or similar. As a result, the teams could not promote a productive discussion that involved all team members working collectively towards making decisions.

Table 8: Student quotes about limited quality of communication.

\begin{tabular}{l}
\hline Low-performing team: \\
\hline "sometimes contributes in a productive way \\
but likes to talk a lot about irrelevant stuff. ie \\
drifts off topic easily" \\
"During meetings, I can sometimes say \\
things that are irrelevant or distracting, \\
primarily as jokes, but this can sometimes \\
impede things." \\
\hline High-performing team: \\
"[Student] should try to stay focused on the \\
task at hand during meetings so as to not \\
distract others and detract from the purpose \\
of the meeting." \\
"My only suggestion is not to get too \\
distracted from the topic we re speaking \\
about during meetings. This way we can \\
accomplish more."
\end{tabular}

As can be seen in Table 7 and Table 8, no substantial differences in tone were seen between low and highperforming team's feedback in this theme. Both had feedback that encouraged team members to work towards communicating more frequently and more on topic. 


\subsection{Appreciation of Team-member's Contributions}

This theme represents comments from a combination of one TEI behaviour (seeking and including the input of others) and two other codes that emerged during the coding process (open-mindedness and statements of value).

In low-performing teams, seeking and including the input of others and a lack of open-mindedness were frequently discussed negatively. While students on high and low performing teams received feedback inviting students to ask their team members for help, only students on low-performing teams received complaints for doing so. As can be seen in the examples in Table 9, seeking and including others was seen of as a sign that a team-member was incapable of doing their own work on their own asking for other's opinions was seen of as asking others to do their work for them.

Additionally, in low-performing teams team-members were also critiqued for not being open-minded or for disparaging the ideas of others on their team, Table 10. This combination of behaviours can create an environment in which a team-member does not want to speak up and share an opinion or ask a question.

Table 9: Student quotes about team members being critiqued for asking for the input of others.

"he seems to lack confidence in his own interpretation of what needs to be done, and constantly asks others how he should format things, or what to include on a document"

"You sometimes ask for opinions too much trust your instinct."

Table 10: Student quotes about team members being critiqued about not being open-minded to others' ideas. "think you should be more open-minded about other people's opinions and feedbacks and not take everything personally since we're all working towards the same goal at the end"

"should be more open-minded about other people's opinions and stop criticizing ideas.”

In high-performing teams, by contrast, there were no complaints about students asking other team members for input on their work or about being closed-off to the ideas of others. As seen in Table 11, feedback instead discussed the unique strengths or skills that students brought to their teams. These statements came across in one of two forms - as a skill that was an asset to the work created, or as a behaviour or character attribute without which the team felt they could not have succeeded.
Table 11: Student quotes about team members being appreciated and leveraged for their strengths.

"[Student] taught me how to make more accurate consistent drawing in the room. This voluntary teaching help me become better at explaining my ideas and concepts to the group on the spot."

"I think she really does a great and important job in our group since she has a good understanding of our project she always provide some fantastic ideas about our project."

In comparing high and low performing teams along this theme, appreciation for the different types of value a teammember can bring to the team appears to differentiate the feedback. In high-performing teams, team-members were appreciated for sharing knowledge and for helping the team grow in its capabilities and create better work products. By contrast, in low-performing teams instead the questioning and ideas that could lead to the collective development of great work appear to be limited by team-members who think they know better, or do not find value in supporting their fellow team members.

\section{DISCUSSION}

Comparing the behavioural differences and issues they create among team-members, there appears to be a difference in the orientation that high and low-performing teams have to their design teamwork.

With respect to the first two issues discussed - needing to do more work than assigned, and difficulty working ahead of deadlines - there appears to be a difference in group vs team mindset. Low-performing team feedback presents the picture of a group orientation to their work that work can be divided up, individually conquered, and at the last minute stuck back together. This is evident in the vocabulary of student comments about their design work in Table 3 where students are instructed to do more than their "task" or "parts" and in Table 4 with the timelines discussed by students in their complaints. By contrast, students on high performing teams discussed organising the work that is more focused on a collective team orientation - that individual work needed to be done far enough in advance so that the entire team could bring the project together into a coherent whole. This can be seen in student's vocabulary in Table 3 where students refer to their or the team's responsibilities as 'work' (rather than 'parts' or 'tasks') which implies a sense of a bigger whole that all are contributing to, and in Table 4 where working in advance of deadlines impeded the team's ability to collectively review the deliverable instead of simply not sticking it together by the deadline.

With respect to the issues that were unique to high and low performing teams - High: difficulty scheduling 
meetings, and leveraging others' skills for the team; Low: workload unevenly distributed, asking for help discouraged, being closed to others' opinions - two key differences are apparent.

In low performing teams, there appears to be a distrust of other individuals on the team's abilities to contribute effectively to the team. This is apparent in students trying to take control of the project by themselves, as seen in Table 6, and in seeing the action of asking for help as incompetence on the part of the asker, Table 9. It is possible that this distrust also influenced the way some students heard the ideas of others, and that if they heard an idea from someone they did not trust to be competent that they would be closed to that idea - explaining the lack of openmindedness discussed in Table 10. No grades data was available in this study to explore the sources of student distrust of competence.

In high-performing teams, members appeared to value the skills and contributions of all team members, which was apparent in the collective orientation to work. Student discussions of scheduling meetings in Table 5 implies a desire to discuss ideas with the team and get team input on the work. Similarly, students discussed learning from each other and how valuable team members were to the project, Table 11. This connects strongly to team mindset discussed earlier - that there is value in having everyone's input on the work and that everyone brings value to the team and the project through the perspectives and skills that they share.

It is important to note that there were no differences in how high and low performing teams discussed their desires to have more and higher-quality communication. While this was discussed much more in low-performing teams, it was not presented with a tone that indicates a different motivation for the communication than high-performing teams. As a result, if practitioners are looking for a quick way to move a low performing team to a high performing team, this may be an area in which increased instructional effort will be of significance.

\section{CONCLUSIONS}

This paper presents a comparison of the mid-project intra-team feedback provided by first-year engineering design students to their team members at two universities. Analysis indicates that there are three themes of issues that describe the behavioural differences between high and low performing teams. Quality and quantity of communication was an issue experienced similarly by both groups of teams, whereas the organisation of the team's work and appreciation of team member's contributions were discussed differently. Differences in how students discussed these last two themes of issues indicate that low performing teams may have a different mindset to their work than high-performing teams, and may have an inherent distrust of the competence of their team members. High-performing teams by contrast have a collective orientation to their work that attempts to leverage the skills and perspectives of all team members in all parts of the work.

While this study presents hypotheses as to the differentiating factors between high and low performing teams it must be noted that the issues discussed herein may not be representative of all first-year engineering design teams. Findings here are presented as potential issues for instructors to look for in their design teams with a way of understanding the implications of those issues.

\section{References}

[1] ABET, 2012. [Online]. Available: http://www.abet.org/uploadedFiles/Accreditation/Accred itation_Process/Accreditation_Documents/Current/eaccriteria-2012-2013.pdf..

[2] Canadian Engineering Accreditation Board, "Accreditation Criteria and Procedures," 2010. [Online]. Available: http://engineerscanada.ca/e/files/Accreditation_Criteria_ Procedures_2010.pdf. [Accessed 6 May 2011].

[3] B. Hyman, Fundamentals of Engineering Design, Upper Saddle River, NJ: Prentice-Hall, 2003.

[4] R. Bierhals, I. Schuster, P. Kohler and P. Badke-Schaub, "Shared mental models - Linking team cognition and performance," CoDesign, vol. 3, no. 1, pp. 75-94, 2007.

[5] R. W. Lingard, "Teaching and Assessing Teamwork Skills in Engineering and Computer Science," Journal of Systemics, Cybernetics and Informatics, vol. 8, no. 1, pp. 34-37, 2010.

[6] M. Borrego, J. Karlin, L. D. McNair and K. Beddoes, "Team Effectiveness Theory from Industrial and Organizational Psychology Applied to Engineering Student Project Teams: A Research Review," Journal of Engineering Education, vol. 102, no. 4, pp. 472-512, 2013.

[7] P. K. Sheridan, P. M. To, G. J. Evans and D. W. Reeve, "An On-line Team-effectiveness Learning System," in Proceedings of the Canadian Engineering Education Annual Conference, Canmore, AB, 2014.

[8] P. K. Sheridan, G. J. Evans and D. Reeve, "Teaching Team-effectiveness in Large Classes," Higher Education Quality Council of Ontario, Toronto, 2015.

[9] D. Gatchell, D. Ankenman, P. Hirsch, A. Goodman and K. Brown, "Restructuring teamwork pedagogy in a firstyear engineering design program: Lessons learned and future plans," in American Society for Engineering Education Annual Conference \& Exposition, Indianapolis, IN, 2014.

[10] D. Gatchell, P. Hirsch, A. Goodman, J. Anderson, S. Carr and B. Ankenman, "Facilitating Teamwork Instruction in a First-Year Engineering Design Program: a Question of Balance," in 5th First Year Engienering Experience Conference, Pittsburgh, PA, 2013. 